\title{
Effect of Pump Rate Penetration Sensitivity on Hydraulic Fracturing in Low Resistivity Reservoir
}

\author{
Harry Budiharjo Sulistyarso \\ Department of Petroleum Engineering, UPN “Veteran” Yogyakarta, D. I. Yogyakarta, Yogyakarta, Indonesia Indonesia \\ Email address: \\ harry_hb@upnyk.ac.id, harry_budiharjo@yahoo.com \\ To cite this article: \\ Harry Budiharjo Sulistyarso. Effect of Pump Rate Penetration Sensitivity on Hydraulic Fracturing in Low Resistivity Reservoir. Petroleum \\ Science and Engineering. Vol. 3, No. 1, 2019, pp. 10-16. doi: 10.11648/j.pse.20190301.13
}

Received: February 19, 2019; Accepted: March 26, 2019; Published: April 18, 2019

\begin{abstract}
Hydraulic fracturing is one of the stimulation methods to increase rock permeability. Hydraulic fracturing is commonly used in reservoir that have low permeability and wells which have a decline in production rate. In many cases, hydraulic fracturing show significant success which is marked by an increase in the production rates. In this paper, hydraulic fracturing will be conducted by observing the effects of pumping rates. A case example is taken from an oil well that has a low resistivity reservoir, which is HAP\#532 well. This low resistivity causes the reservoir to have low permeability and small production rates. The scenario of hydraulic fracturing in HAP\#532 well is done by using several different pumping rate sensitivity, start from 10 BPM, 20 BPM, and 30 BPM, as based on 15 BPM base case pumping rates to obtain the most optimal pumping rate. Therefore, it can be seen how much the effect of pumping rates on hydraulic fracturing. From three scenarios performed by using FracCADE and Prosper, author get the optimal pumping rate is $20 \mathrm{BPM}$. At this pumping rate, the fracture geometry obtained fracture half-length (Xf) is $213 \mathrm{ft}$, fracture height (hf) is $45.6 \mathrm{ft}$, fracture width (Wavg) is 0.56 inch, average permeability is $58.09 \mathrm{mD}$, and the production rate is $348 \mathrm{BOPD}$.
\end{abstract}

Keywords: Hydraulic Fracturing, Low Resistivity Reservoir, Pumping Rate, Stimulation

\section{Introduction}

In the past, most of reservoir targets were directed to good reservoir properties and produced through producing wells without treatment certainly. As time goes by and it is difficult to obtain a target reservoir with good characteristics, the exploitation of oil begins to start at the reservoir with bad characteristics, but has a large hydrocarbon content, which is the reservoir with low resistivity and low permeability value. There are needed an extra effort to be able to produce oil from this type of reservoir, one of the way is by hydraulic fracturing. Reservoirs that incapable of production just 10 years ago can now be economic with horizontal wells and current hydraulic fracturing technology [1]. Hydraulic fracturing performed by injecting the fracturing fluid above the formation pressure to create a new conductivity path. A hydraulic fracturing job is divided into two stages: the pad stage and the slurry stage. In the pad stage, only fracturing fluid is injected into the well to break down the formation and to create a pad. During the slurry stage, the fracturing fluid is mixed with sand/proppant in a blender and the mixture is injected into the pad/fracture. After filling the fracture with proppant, the fracturing job is finished and the pump is shut down [2]. The effect of pump schedule was studied by many authors before, one of the author is Ciezobka [3] proposed a method of pumping hydraulic fracture stages in shale formation where the fluid pump rate is rapidly changed from the maximum rate, to some significantly lower rate, and then rapidly increased back to original maximum rate. Some previous authors only focused on reservoirs that were known to have oil content. In this paper, the author focuses on low resistivity reservoir that have low permeability and low readings on resistivity logs but have a large hydrocarbon content. The sensitivity of pump rate on hydraulic fracturing must be done as good as possible so that the optimal fracture geometry can be obtained and increase the rate of production. In this study, FracCADE and Prosper simulator was used to make a hydraulic fracturing design. The case study presented is the HAP\#532 well located in West Java, Indonesia. 


\section{Literature Review}

\subsection{Low Resistivity Reservoir}

According to Austin, Boyd., et all [4], low resistivity reservoir has resistivity value between 0.5-5 ohm-m on resistivity log readings and difficult to distinguish between zones containing hydrocarbons and zones containing water. Low resistivity reservoir phenomena often occur in sediments filled with clay minerals which is distributed laminar up to shale and the presence of conductive minerals in the form of pyrite. Lamination is defined the layer that has a thickness of less than $1 \mathrm{~cm}$ [5]. The presence of shale lamination causes inaccurate readings in conventional logs. Meanwhile, clay minerals have a negative surface charge which causes the log resistivity to decrease drastically. This negative surface charge attracts cations such as $\mathrm{Na}^{+}$and $\mathrm{K}^{+}$. When clay minerals meet with water, cations are released, resulting in increased water conductivity and a decrease in resistivity [6]. In addition, the presence of conductive minerals will result in low levels of accuracy in evaluating water saturation [7], due to having high conductivity such as iron (Fe) minerals. So that the calculation of water saturation becomes excessive and does not match with the actual conditions.

\subsection{Hydraulic Fracturing}

Hydraulic fracturing is a stimulation technique used to increase or improve the productivity of wells to make conductive channels that could penetrate damaged zones (skin). To achieve this goal, a fracture is made which functions as a way of flowing reservoir fluid into the wellbore by injecting certain fluid at a pressure above the formation fracture pressure. This fluid is continuously injected to widen the fracture. The fracture that occurs is given a proppant to keep the fracture from closing again and must be able to flow the fluid. Therefore the proppant should be have a large permeability and strength that is good enough to not be easily destroyed by high pressure and temperature [8]. The hydraulic fracturing scheme is shown in Figure 1.

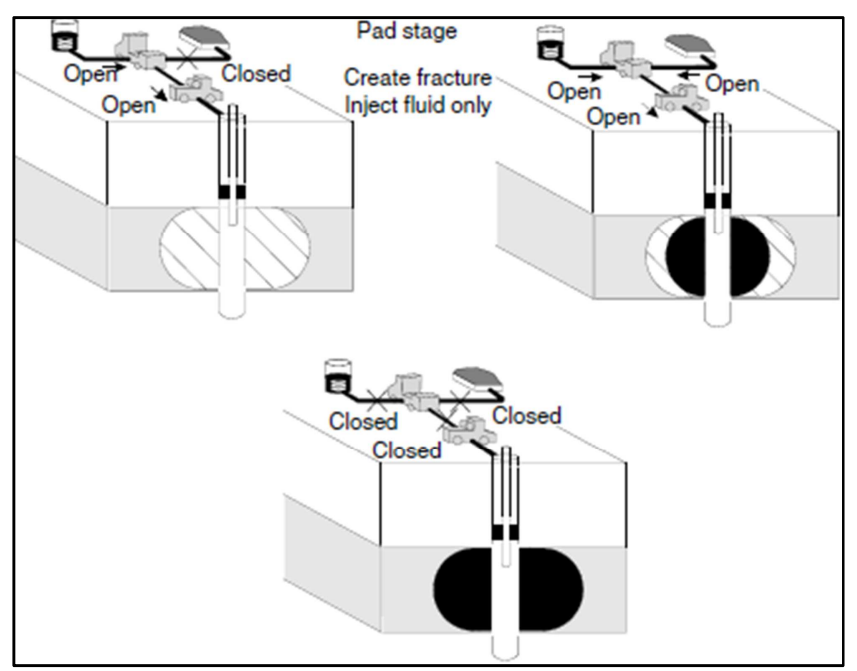

Figure 1. Scheme of Hydraulic Fracturing [2].
There are three important types of pressure in hydraulic fracturing, which are fracture initiation pressure, fracture propagation pressure and closure pressure (Figure 2). The fracture initiation pressure is the pressure in the wellbore that is needed to break the formation for the first time, while the propagation pressure is a stable injection pressure over a long period of time during the fracturing process to create fracture geometries (length, height, and width) based on the design. The closure pressure is the pressure where the fracture is closed again after fluid injection and the proppant placement have been completed.

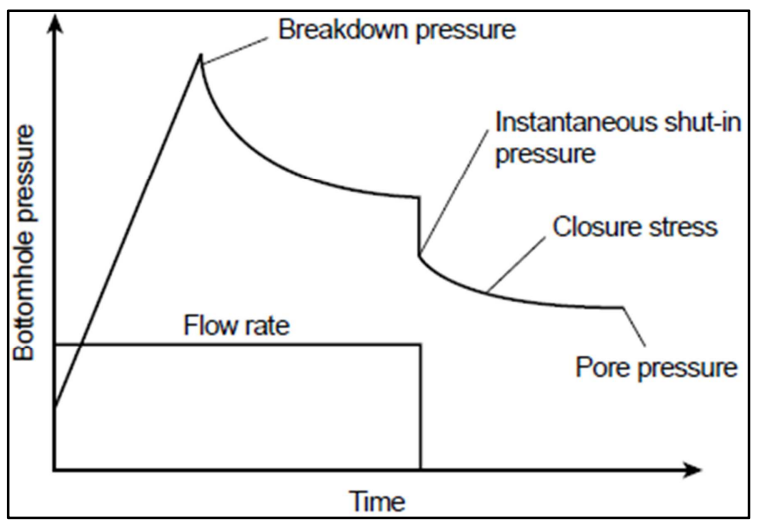

Figure 2. Pressure vs Time in Hydraulic Fracturing Process [9].

In hydraulic fracturing, physical properties, type, thickness, rock stress, and formation depth are very influential in determining the direction of fracture. The rock stress itself is divided into three parts, $\sigma_{\mathrm{v}}$ : vertical stress, $\sigma_{\mathrm{hmax}}$ : maximum horizontal stress; $\sigma_{\mathrm{hmin}}$ : minimum horizontal stress, where $\sigma_{\mathrm{v}}>$ $\sigma_{\text {hmax }}>\sigma_{\text {hmin }}$. The direction of the fracture will be perpendicular to $\sigma_{\text {hmin }}$ as shown in Figure 3. The value and direction of the three main stresses (in-situ stress) greatly affect the dimensions and orientation of the fracture. For shallow reservoir (less than 1,000 $\mathrm{ft}$ ), the way of the minimum stress (least principle stress) tends to be vertical so that the way of the fractures to be horizontal. The fracture pressure will push and open the cleat perpendicular to the minimum stress, this is occurs because the overburden pressure from the formation above is relatively smaller. For depths of more than $1,000 \mathrm{ft}$, fractures are usually vertical because the main overburden pressure will be even greater [9].

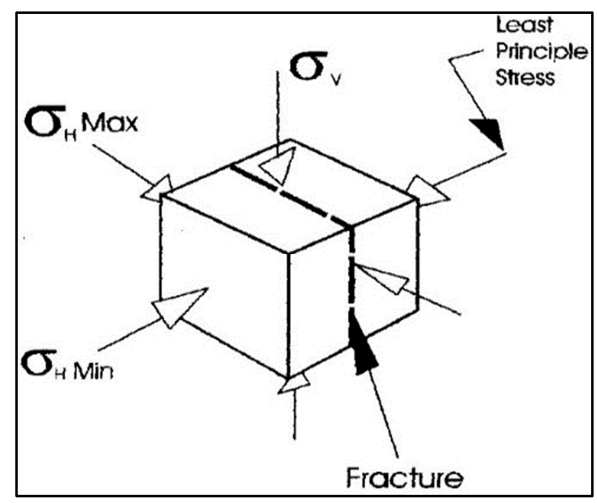

Figure 3. Main Stresses and Fracture Direction [9]. 
Pumping rates also influence to the fracture geometry besides rock characteristics and reservoir depth. The pumping rate must have a pressure greater than the fracture pressure of the formation to be able to break the formation for the first time. The pumping rate and pressure will be stabilized to create a fracture that is longer and wider until the limitation reaches. In the end, the injection fluid with the proppant is done up to the proppant reaches the end of the fracture occured, and then the pump is stoped [10].

The calculation of increased permeability and Inflow Performance Relationship will be performed after the fracture occured. In the fracture geometry results using FracCADE simulator where the simulation will get some results such as fracture half-length $\left(\mathrm{X}_{\mathrm{f}}\right)$, fracture height $\left(\mathrm{h}_{\mathrm{f}}\right)$, fracture width $\left(\mathrm{W}_{\mathrm{avg}}\right)$ and conductivity $\left(\mathrm{Wk}_{\mathrm{f}}\right)$. The assumptions used for calculation of permeability is the value around the wellbore to be different in the zone that is far from the wellbore (discontinous radial permeability). The value of permeability $\left(\mathrm{k}_{\mathrm{f}}\right)$ and the value of average permeability $\left(\mathrm{k}_{\mathrm{avg}}\right)$ with the Howard and Fast method can be calculated by the following equation:

$$
\begin{gathered}
\mathrm{k}_{\mathrm{f}}=\frac{\left(\mathrm{k}_{\mathrm{i}} \times \mathrm{h}\right)+\mathrm{Wk} \mathrm{k}_{\mathrm{f}}}{\mathrm{h}} \\
\mathrm{k}_{\text {avg }}=\frac{\log \frac{\mathrm{r}_{\mathrm{e}}}{\mathrm{r}_{\mathrm{w}}}}{\left[\left(\frac{1}{\mathrm{k}_{\mathrm{f}}}\right) \log \left(\frac{\mathrm{X}_{\mathrm{f}}}{\mathrm{r}_{\mathrm{w}}}\right)\right]+\left[\left(\frac{1}{\mathrm{k}_{\mathrm{i}}}\right) \log \left(\frac{\mathrm{r}_{\mathrm{e}}}{\mathrm{x}_{\mathrm{f}}}\right)\right]}
\end{gathered}
$$

The last calculation done after knowing the fracture geometry that was formed and the permeability after the fracture is to calculate the production rate. The production rate is calculated using Prosper simulator and then analyzes the most optimal flow rate from some of the pump rates that have been simulated.

\section{Work Procedures}

In this study, the authors used the FracCADE simulator to simulate the fractures that occur, which are fracture halflength $\left(\mathrm{X}_{\mathrm{f}}\right)$, fracture height $\left(\mathrm{h}_{\mathrm{f}}\right)$, average fracture width $\left(\mathrm{W}_{\mathrm{avg}}\right)$, and conductivity $\left(\mathrm{Wk}_{\mathrm{f}}\right)$. Permeability can be calculated using the Howard and Fast equation after fracture geometry obtained. The last analysis is done by calculating the production rate using the Prosper simulator. In the FracCADE simulator, the same type of fluid and proppant will be selected in each scenario, the scenario based on the current condition in HAP\#532 well. We start from 10 BPM, 20 BPM, and 30 BPM pump rates. The difference in fracture results from the pumping rate sensitivity will be analyzed further to determine the most optimal pumping rate for the production rate using the Prosper simulator.

\section{Case Study}

There was one case of hydraulic fracturing in a field in West Java, Indonesia, which is the HAP\#532 well that performed in June 2012. From the DST test conducted at this field in several wells including the HAP\#532 well, results were not satisfactory and not even produce oil at all. The HAP\#532 well is one of the well that cannot produce, therefore it is temporarily shut-in. This HAP\#532 well is a well located in the offshore that produces oil in a reservoir from a depth of 7,530-7,550 ft MD with a thickness around $45 \mathrm{ft}$ in a Massive formation. The hydraulic fracturing performed successfully flow the oil from the HAP\#532 well around 273 BOPD with a pumping rate of $15 \mathrm{BPM}$. The HAP\#532 well oil zone originates from a reservoir that has a low resistivity value around $1.8 \Omega \mathrm{m}$ to $2.5 \Omega \mathrm{m}$ and low permeability of $10 \mathrm{mD}$, but has considerable hydrocarbon reserves around 16-46 $\mathrm{MMBO}$ and reservoir pressure still high around 2,517 psi. Complete information about the reservoir in the HAP\#532 well can be seen in Table 1 and Table 2.

Table 1. Reservoir Data.

\begin{tabular}{lll}
\hline Parameter & Unit & Value \\
\hline Porosity & $\%$ & 20 \\
Permeability & $\mathrm{mD}$ & 10 \\
Water Cut & $\%$ & 70 \\
Reservoir Temperature & ${ }^{\circ} \mathrm{F}$ & 210 \\
Reservoir Thickness & $\mathrm{ft}$ & 45 \\
Oil Gravity & ${ }^{\circ} \mathrm{API}$ & 37 \\
Ps & $\mathrm{psig}$ & 2,517 \\
\hline
\end{tabular}

Table 2. HAP\#532 Well Completion Data.

\begin{tabular}{llll}
\hline Parameter & Notation & Unit & Value \\
\hline Casing Outside Diameter & OD $_{\mathrm{c}}$ & in & 7 \\
Casing Inside Diameter & ID & in & 6.366 \\
Tubing Outside Diameter & OD & in & 3.5 \\
Tubing Inside Diameter & ID & in & 2.992 \\
Well Radius & $\mathrm{r}_{\mathrm{w}}$ & $\mathrm{ft}$ & 0.125 \\
Drainage Radius & $\mathrm{r}_{\mathrm{e}}$ & $\mathrm{ft}$ & 820 \\
Top Perforation (MD) & $\mathrm{T}_{\text {perf }}$ & $\mathrm{ft}$ & 7,530 \\
Bottom Perforation (MD) & $\mathrm{B}_{\text {perf }}$ & $\mathrm{ft}$ & 7,550 \\
Mid Perforation Depth & $\mathrm{D}$ & $\mathrm{ft}$ & 7,540 \\
\hline
\end{tabular}

In this case study, hydraulic fracturing will be designed with three scenarios based on the hydraulic fracturing experience above (as base case), which are the first scenario uses a pumping rate of $10 \mathrm{BPM}$, the second scenario is 20 $\mathrm{BPM}$, and the third scenario is $30 \mathrm{BPM}$. The fluid that used is a type of water-based fluid (crosslinked fluid PrimeFRAC 30 $+5 \mathrm{lbs} \mathrm{J} 481$ and $2 \% \mathrm{KCL}$ water) with total fluid of 19,010 gallons. In addition, proppant that used is 20/40 CarboLITE, this is a proppant that suitable for low resistivity reservoir. From the three scenarios that have been done, it will be analyzed how much influence the pumping rate on fracture geometry, permeability and production rate, so that the optimal pumping rate can be obtained.

\section{Result and Discussion}

Based on work procedures, author calculated the fracture geometry (fracture half-length, fracture widht, fracture height, and conductivity) by using FracCADE simulator, increased permeability using Howard and Fast equation, and also increased production rate using Prosper simulator. 


\subsection{Fracture Geometry}

The fracture model using the PKN method, because the fracture half-length $(193 \mathrm{ft})$ exceeds the fracture height (45.6 $\mathrm{ft}$ ). From the three scenarios that performed using the FracCADE simulator, the results can be seen in Table 3, while the fracture and conductivity profiles in each scenario can be seen in Figure 4 to Figure 7.

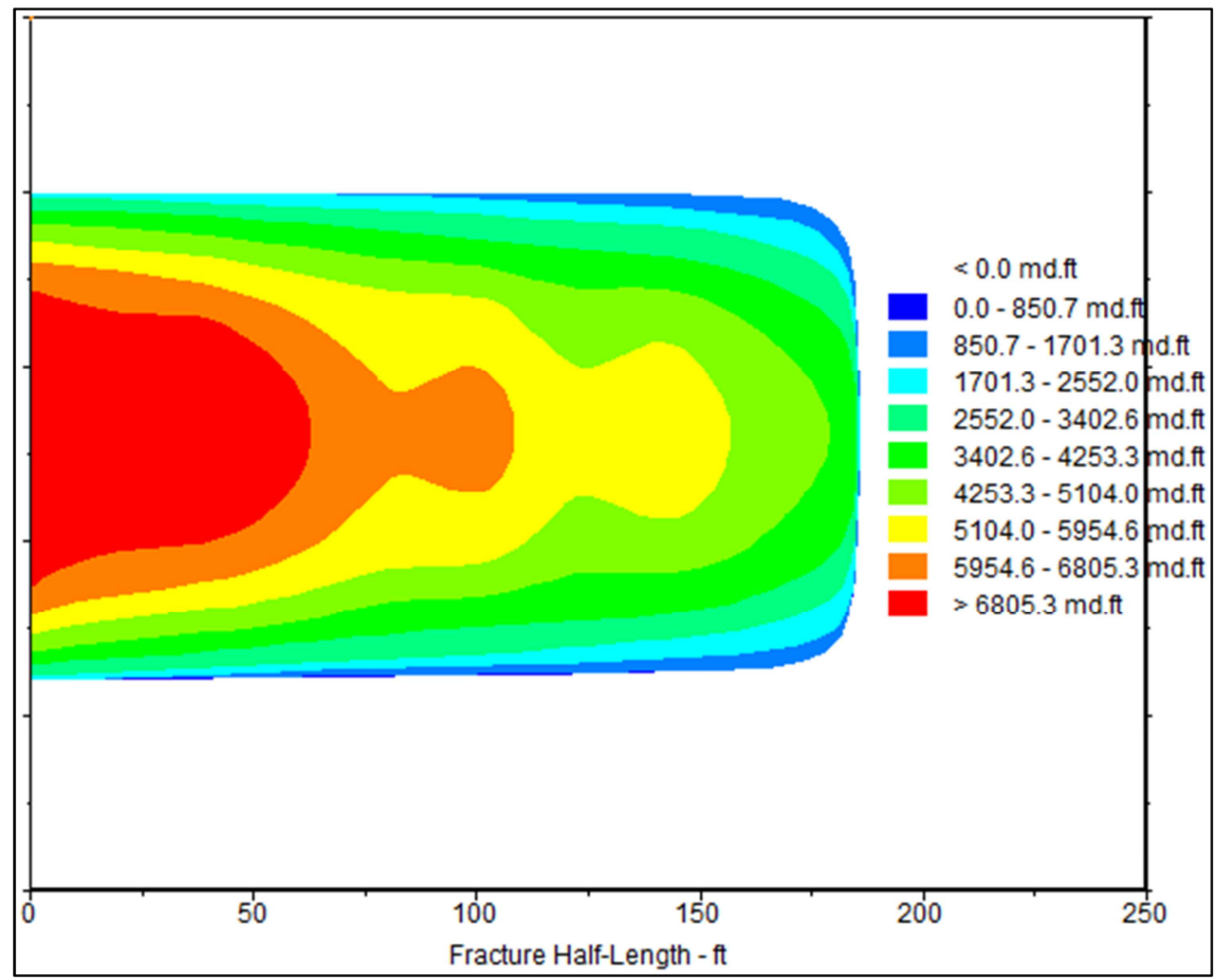

Figure 4. Base case Fracture Profile.

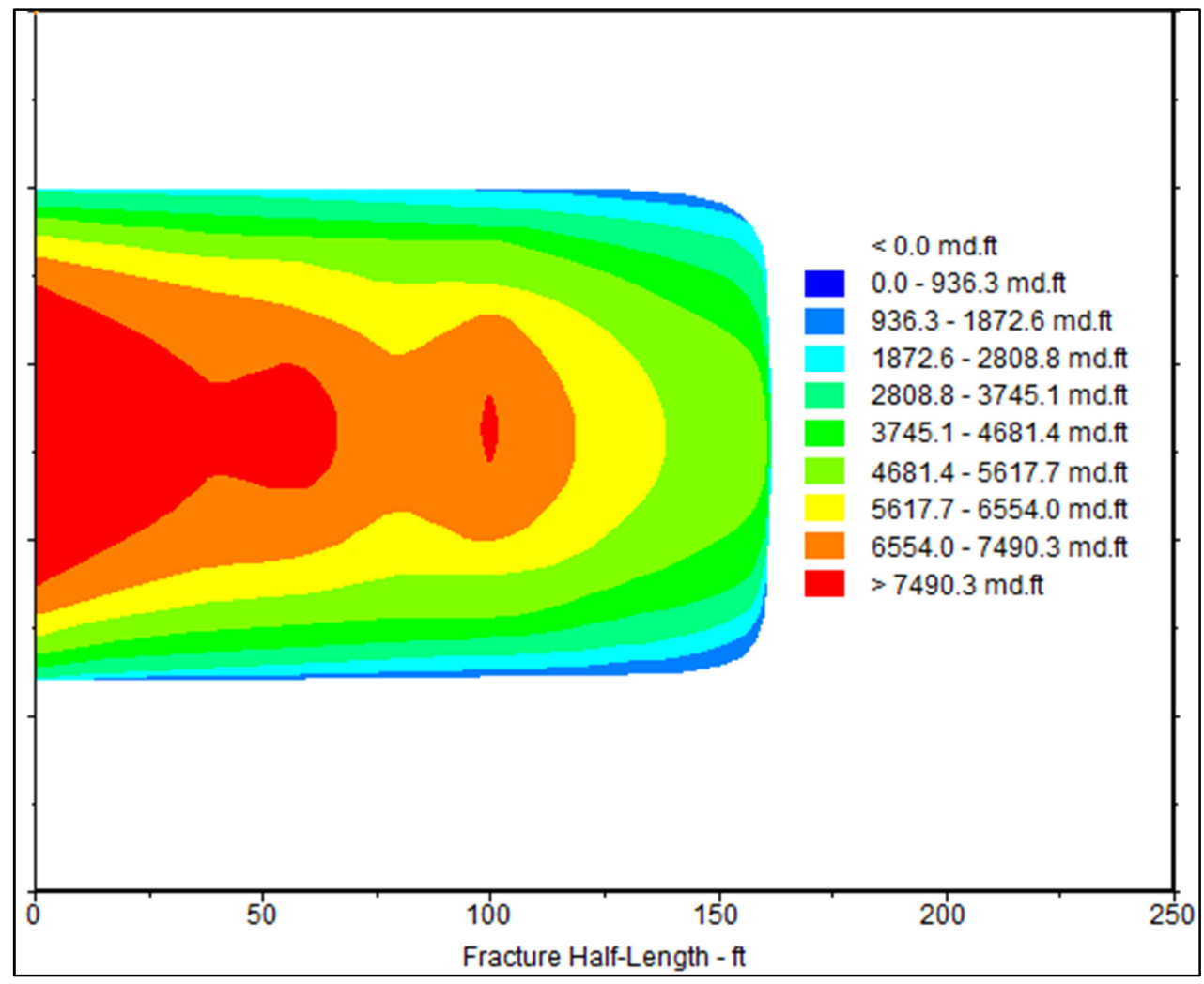

Figure 5. First Scenario Fracture Profile. 


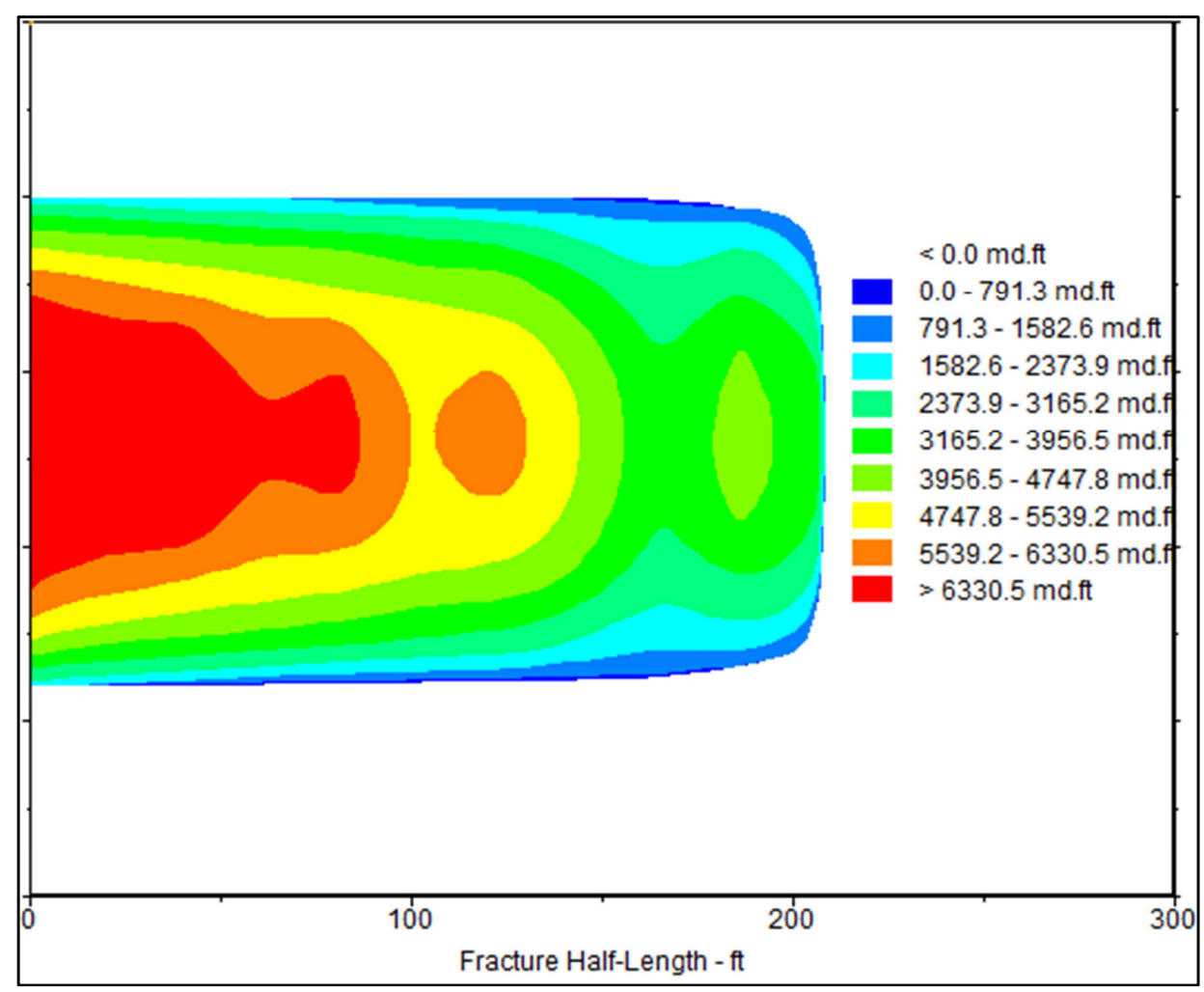

Figure 6. Second Scenario Fracture Profile.

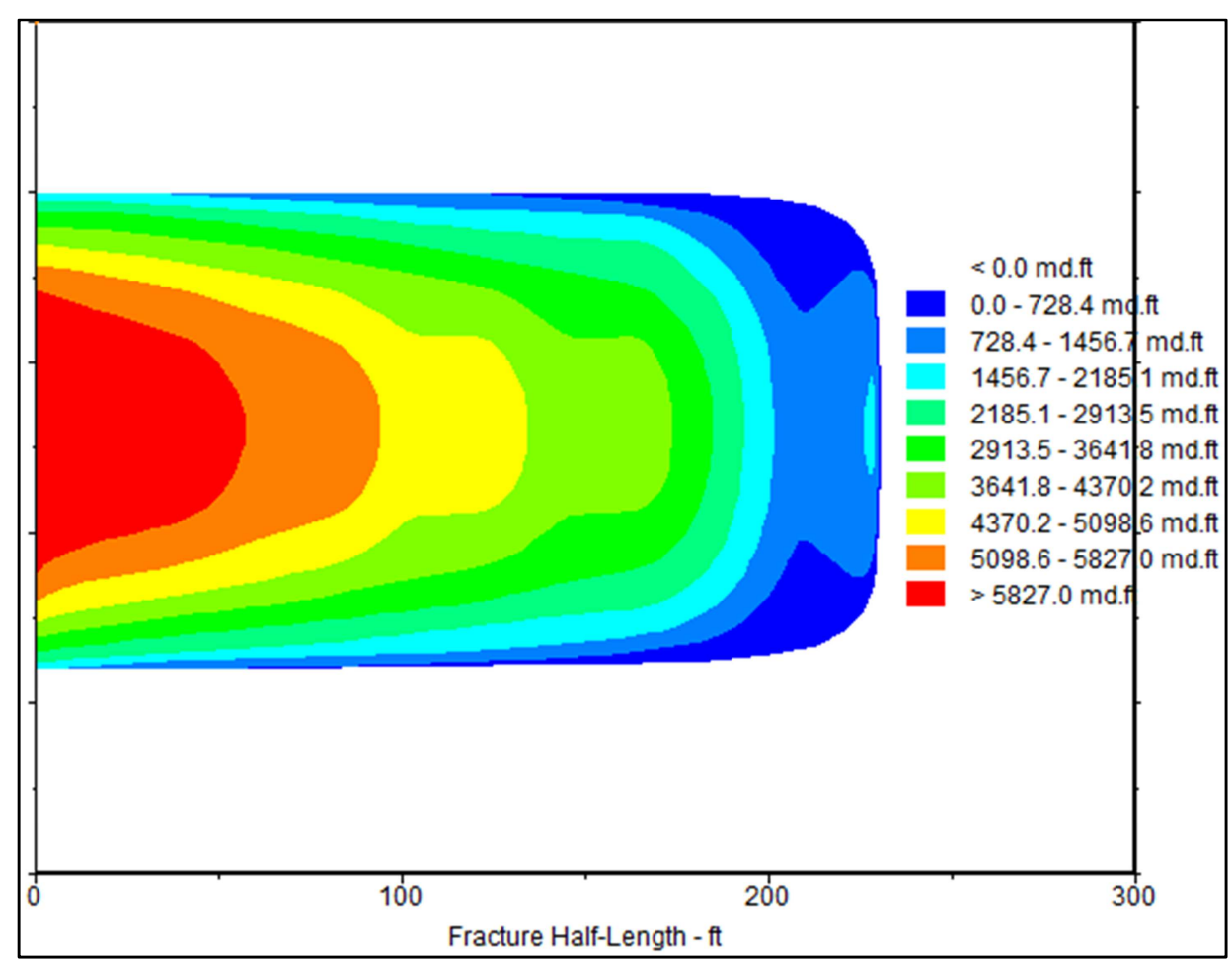

Figure 7. Third Scenario Fracture Profile.

Table 3. Result of Fracture Geometry.

\begin{tabular}{lllll}
\hline Paramater & Base case (15 bpm) & First Scenario (10 bpm) & Second Scenario (20 bpm) & Third Scenario (30 bpm) \\
\hline $\mathrm{X}_{\mathrm{f}}$ & $193 \mathrm{ft}$ & $168 \mathrm{ft}$ & $213 \mathrm{ft}$ & $241 \mathrm{ft}$ \\
$\mathrm{W}_{\text {avg }}$ & $0.52 \mathrm{inch}$ & $0.65 \mathrm{inch}$ & $0.56 \mathrm{inch}$ & $0.53 \mathrm{inch}$ \\
$\mathrm{h}_{\mathrm{f}}$ & $45.6 \mathrm{ft}$ & $45.6 \mathrm{ft}$ & $45.6 \mathrm{ft}$ & $45.6 \mathrm{ft}$ \\
$\mathrm{Wkf}$ & $3,052 \mathrm{mD} . \mathrm{ft}$ & $5,602 \mathrm{mD} . \mathrm{ft}$ & $4,061 \mathrm{mD} . \mathrm{ft}$ & $2,134 \mathrm{mD} . \mathrm{ft}$ \\
\hline
\end{tabular}


From Table 3, it can be seen that the higher the pumping rate given, the greater the fracture half-length value $\left(\mathrm{X}_{\mathrm{f}}\right)$, otherwise for fracture width $\left(\mathrm{W}_{\mathrm{avg}}\right)$ there are no significant changes occured, and for fracture height $\left(\mathrm{h}_{\mathrm{f}}\right)$ there are no changes at all. Moreover the conductivity value decreases as the pumping rate increases. This happened because, even though the fracture that formed is longer, the fracture with the largest width is near the borehole, the longer the fracture, so the fracture width formed will be smaller. Therefore, it obtained the lower average conductivity in long fractures compared to short fractures.

\subsection{Increased Permeability}

The first value of permeability in the reservoir is $10 \mathrm{mD}$. Calculation of permeability after hydraulic fracturing was performed using the Howard \& Fast method (Equations 1 and 2). First, the calculation of the formation permeability is done, then the average permeability can be calculated. The calculation results can be seen in Table 4 below:

Table 4. Result of Increased Permeability.

\begin{tabular}{llll}
\hline Parameter & Base case (15 bpm) & First Scenario (10 bpm) & Second Scenario (20 bpm) \\
\hline Formation Permeability $\left(\mathrm{k}_{\mathrm{f}}\right)$ & $350.8 \mathrm{mD}$ & $605.8 \mathrm{mD}$ & $451.7 \mathrm{mD}$ \\
Average Permeability $\left(\mathrm{k}_{\mathrm{avg}}\right)$ & $53.07 \mathrm{mD}$ & $51.5 \mathrm{mD}$ & $58.09 \mathrm{mD}$ \\
\hline
\end{tabular}

From Table 4 above, it can be seen that there is a big difference between formation permeability and average permeability obtained. This is happened because in the fracturing process, the formed permeability is not good distributed throughout the fracture path. There is a big difference between the permeability of fractures near and far from the borehole. This case is the same as conductivity, where as the length of the fracture increases, conductivity will decreases. Therefore, the longer the fracture, the smaller the permeability will be formed.

\subsection{Increased Production Rate}

The end goal of this study is to calculate the increasing production rate. Author use "Hydraulically Fractured Well Model" by using Prosper simulator. From several fracture half-length $\left(\mathrm{X}_{\mathrm{f}}\right)$ that occured, an Inflow Performance Relationship curve can be created. The inflow performance of the well, a relationship between flowing bottomhole pressure and producing rate, represents the ability of a well to deliver oil/gas from the reservoir to the wellbore [11]. The results are at the base case is 1,196 BLPD, first scenario is $1,320 \mathrm{BLPD}$, second scenario is 1,444 BLPD, and third scenario is 1,010 BLPD. The Inflow Performance Relationship curve can be seen in Figure 8.

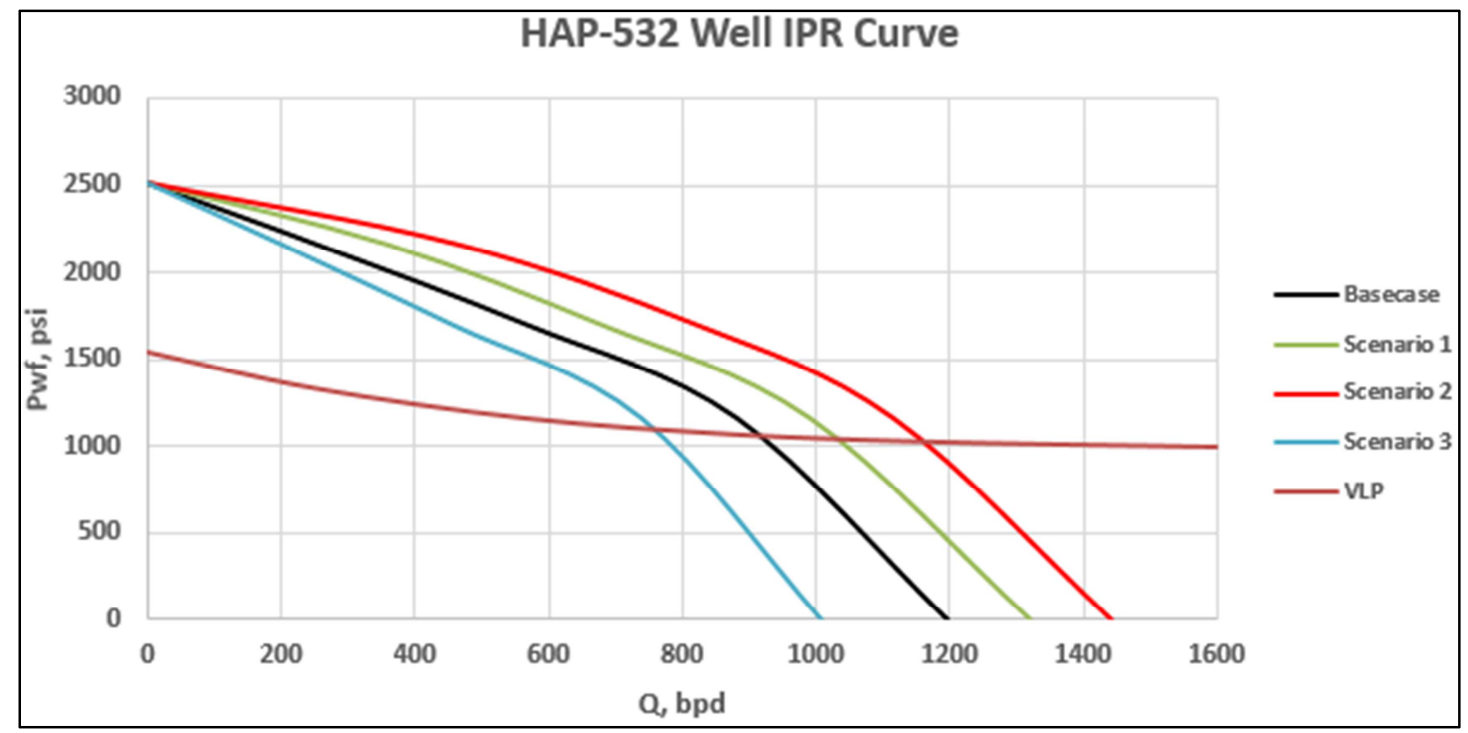

Figure 8. HAP\#532 Well IPR Curve.

Based on the IPR curve above, it can be seen that the fracture geometry (base case) is still not optimal. Because of that, author do the analysis with sensitivity of pumping rates. Start from 10 BPM, 20 BPM, and 30 BPM. It can be seen that in the second scenario, the pumping rate of $20 \mathrm{BPM}\left(\mathrm{X}_{\mathrm{f}}\right.$ $=213 \mathrm{ft}$ ) results in the largest and optimal production rate. For this HAP\#532 well, it has a water cut of $70 \%$, then the oil production rate is obtained in each base case; first scenario; second scenario, and third scenario is 273 BOPD;
314.5 BOPD; 348 BOPD; and 225.6 BOPD with Vertical Lift Performance using 2.992 inch tubing and well head pressure 180 psig. The longer the fracture does not guarantee that there will be an increase in the rate of production, as shown in Figure 8. This is happened because the longer the fracture will be farther away from the wellbore and make the permeability becomes smaller which results in the smaller conductivity too. 


\section{Conclusion}

The effect of the different pump parameters on hydraulic fracturing that performed in low resistivity reservoir was presented through this study using data from HAP\#523 well. The results show that from the three pumping rate scenarios performed, the results obtained in each scenario are in the first scenario 10 BPM is $314.5 \mathrm{BOPD}$, the second scenario 20 $\mathrm{BPM}$ is $348 \mathrm{BOPD}$, and in the third scenario $30 \mathrm{BPM}$ is 225.6 BOPD. The reservoir that produces the largest oil production rate is in the second scenario with a pumping rate of 20 BPM producing 348 BOPD. From the results, it can conclude that the increased pumping rate will increase fracture half-length, but decrease fracture conductivity. So that the increase in pumping rate does not guarantee an increases in production rate, this depends on the value of permeability and fracture conductivity that occurs.

\section{References}

[1] Crain, E. R., (2016). "Crain's Petrophysical Pocket Pal". Course Reference Manual, Self Published. pp. 2.

[2] Guo, B., Lyons, W., and Ghalambor, Ali,. (2007). "Petroleum Production Engineering a Computer assisted Approach". Elsevier, pp. 253, 255-257, 260.

[3] Ciezobka J, Maity D, Salehi I., (2016) "Variable pump rate fracturing leads to improved production in the Marcellus Shale". Society of Petroleum Engineers. SPE Hydraulic Fracturing Technology Conference, Texas, USA. pp. 1-2.
[4] Austin, Boyd., Darling, Halord., Tabanou, Jacques., et all., (1995). "The Lowdown On Low Resistivity Pay". Oilfield Review Journal, pp. 1-3.

[5] Tucker, M. E., (2003). "Sedimentary Rock in the Field", John Wiley \& Sons, Ltd: New York. ISBN: 0-470-85123-6, pp. 88.

[6] Hamada, G., and Al-Awad, M., (2000). "Petrophysical Evaluation of Low Resistivity Sandstone Reservoirs". Journal of Canadian Petroleum Technology. Volume 39, No. 7, pp. 13.

[7] Worthington, Paul, (1997). "Recognition and Development of Low-Resistivity Pay". SPE Asia Pasific Oil and Gas Conference, Kuala Lumpur, Malaysia, April 14th-16th, 1997. SPE 38035, pp. 3,8 .

[8] Brady, Barry., Elbel, Jack., et all., (1992). "Cracking Rock: Progress in Fracture Treatment Design". Oilfield Review Journal, pp. 3.

[9] Economides, J. Michael, and Boney, C., (2000). "Reservoir Stimulation in Petroleum Production", Wiley, New York, pp. 80, 99, 107.

[10] Khair, Elham, (2017). "Effect of Pump Schedule on Fracture Geometry and Shape during Frac Packing Job". Journal of Petroleum Environmental Biotechnology. Volume 8, Issue 5, DOI: $10.4172 / 2157-7463.1000342$, pp. 3-4.

[11] Economides, J. Michael, and K. Nolte., (1989). "Reservoir Stimulation", Second Edition, Prentice Hall, Englewood Cliffs, New Jersey, pp. 186. 